\title{
Normative Study of Physical Fitness Test Battery in Secondary School: A Case Report 中學體道能测試常模標準之個案報告
}

\author{
Bilk C. Chow \\ Department of Physical Education, \\ Hong Kong Baptist University, HONG KONG \\ 周碧珠 \\ 香港浸會大學體育學系
}

\begin{abstract}
This paper presents a normative study of physical fitness test battery for a local secondary school in New Territories. Test items include hand grip; 30-sec flexed knee sit-ups; sit and reach; endurance run of $800 \mathrm{~m}$ (girls) and 1000m (boys); and Bailey Bridge test. In order to test for the validity of the Bailey Bridge test, 30-sec straight leg push-ups for boys and knee pushups for girls were also conducted. Norms presented in this paper are categorized by age and gender so that other physical education teachers in secondary schools can use these results for comparison.
\end{abstract}

\section{摘要}

這篇文章介紹新界區一所中學推行之體適能測試獎勵計劃, 測試項目包括手握力、三十秒仰臥起坐、坐前伸、女子 800 公尺、男子 1000 公尺跑及拾放豆袋。另外, 男子三十秒直腳掌上壓及女子曲腳掌上壓爲附加項目, 作用是檢定拾放豆袋測 試之有效度，文章提供的常模標準是按性別和年齡組合，其他中學體育老師可利用這些標準作爲比較依據。

Physical education teachers often incorporate fitness training in their curriculum. Numerous fitness test batteries can be found across countries and regions. For example, in USA, the Fitnessgram (1992) consists of 1-mile run or the Pacer (20 m shuttle run); skinfolds or body mass index; curl-up; push-up or flexed-arm hang or modified pull-up; trunk lift; back saver sit-and-reach or shoulder stretch. The Australian Fitness Education Award (ACPHER,1996) shares similar features with the Fitnessgram. It consists of height, weight and body mass index; $1.6 \mathrm{~km}$ run/walk (i.e. 1 mile) or $20 \mathrm{~m}$ shuttle run (multi-stage); curlup and basketball throw; sit and reach and shoulder stretch. Locally, the Physical Fitness Award Scheme for Secondary Schools (PFASSS) introduced in 1991 by the Education Department and the Hong Kong Childhealth Foundation includes these items: height, weight; hand grip; pull-ups (boys) or flexed arm hang (girls); 30-sec. flexed knee sit-ups; sit \& reach; endurance run of $1000 \mathrm{~m}$ (boys) or $800 \mathrm{~m}$ (girls). Comparing fitness test batteries in the nineties with those in the seventies, the test items nowadays have shifted from the mainly motor-related fitness in the past to the current health-related fitness concept. The other major aspect of changes is the emergence of criterion-referenced standards complimenting the norm-referenced standards in which the normreferenced standards were solely offered in the past. However, discrepancies on the criterion-referenced standards for the same test items were found in the major test batteries in USA.

Those commonly found fitness test items such as 1-mile run, sit-ups and pull-ups/flexed arm hang/push-up, sit-and-reach, and skinfolds are measuring health-related physical fitness components of cardiovascular endurance, muscular strength and endurance, flexibility, and body component, respectively. The items have often undergone testing for validity and reliability. Apart from the test being valid and reliable, a good test has to be easy to administer, requires minimal equipment and can be mass testable. The most problematic item is the measurement of upper shoulder strength and endurance which can be assessed by pull-ups; modified pull-ups; flexed arm hang or push-up (see Chow, 1996 for review). The pull-ups and flexed arm hang tests were criticized for the relatively large percentages of zero scores among girls and younger boys. The modified pull-ups test requires special equipment while the push-up test has the problem for subjects to maintain proper form.

In this academic school year, twelve secondary schools under the Po Leung Kuk group administered their own physical fitness test battery. A task force was set up at the beginning 
of school year to discuss test items. In view of the problems with push-up and pull-ups, they chose the Bailey Bridge Test for assessing upper shoulder strength and endurance (see Table 1 for test description). The other test items of hand grip; 30-sec flexed knee sit-ups; sit and reach; endurance run of $800 \mathrm{~m}$ (girls) and $1000 \mathrm{~m}$ (boys) were adopted which were the same in PFASSS. Using norm-referenced standards for age and sex within the individual schools, fitness awards were set up. Students with results in the top 5\% and the next $20 \%$ for a test item were awarded. Norm-referenced standards between schools were also established. Furthermore, extensive award system based on sport team representations and achievements was also incorporated. For example, one school team representation will be awarded with ten stars. Representation in a territorywide competition or medal winning will result with another ten stars. For an individual event (e.g. 100m run), a student can claim awards up to three representations annually. Finally, badges of gold, silver and bronze and certificates will be awarded to students based on achievement of total stars.

The norms from one secondary school in the New Territories under the Po Leung Kuk group were presented in this paper (see tables 2-9). Physical education teachers of secondary schools can use these norms for comparisons. In order to test for the validity of the newly adopted Bailey Bridge Test item, this school also administered 30-sec straight leg pushup for boys following Fitnessgram (1992) protocol and 30- sec knee push-up for girls. No evidence has been provided on the validity of the Bailey Bridge Test on teenagers. Testing on primary school children, Chow (1997) found that the Bailey Bridge Test was invalid and barely reliable.

\section{References}

ACHPER (1996). User's manual \& curriculum ideas: Australian fitness education award. Australian council for health, physical education and recreation.

Chow, B. C. (1996). Field tests of upper body strength and endurance. PERS Review, 2(2), 30-33.

Chow, B. C. (1997). Validity and reliability of Bailey Bridge test for primary school children. Hong Kong Journal of Sports Medicine and Sports Science, 4, 23-27.

Prudential FITNESSGRAM Test Administration Manual. (1992). Dallas, TX: The Cooper Institute for Aerobic Research.

\section{Acknowledgement}

The author wishes to thank Mr. Walter Lee and Ms. Chan Mei Yee for providing the data.

\section{Table 1. Test Procedures for the Bailey Bridge Test}

* Is used for measuring the dynamic strength of the arms.

* The subject starts the test in the front support position with shoulders near to and facing a box/chair.

* The top of the box/chair should be $45 \mathrm{~cm}$ from the floor.

* Take the bean bag from the top of the box with one hand.

* Place the bean bag on the floor.

* Pick up the bean bag with another hand and place it on the top of the box/chair.

* The number of times that the bean bag is successfully placed on the box/chair in 30 seconds will be recorded.

Table 2. Descriptive Statistics for Fitness Tests - Mean, (Minimum, Maximum)

\begin{tabular}{|c|c|c|c|c|c|c|c|c|c|}
\hline $\begin{array}{ll}\text { Age } \quad(n) & \end{array}$ & \begin{tabular}{|l|} 
Male or \\
Female
\end{tabular} & & $\begin{array}{l}\operatorname{Run}^{1} \\
\text { ec.) }\end{array}$ & $\begin{array}{l}\text { 30-sec Push } \\
\text { up }^{2}\end{array}$ & $\begin{array}{l}\text { 30-sec Sit } \\
\text { up }\end{array}$ & & $\begin{array}{l}\text { 30-sec } \\
\text { Bailey } \\
\text { Bridge }\end{array}$ & $\begin{array}{l}\text { Hand Grip }{ }^{3} \\
\text { (kgf) }\end{array}$ & $\begin{array}{l}\text { Sit\&Reach } \\
\text { (cm) }\end{array}$ \\
\hline$\kappa=13(n=62)$ & Male & 371 & $(242,740)$ & $15 \quad(1,35)$ & $19 \quad(11,32)$ & 15 & $(5,28)$ & $22 \quad(11,39)$ & $24 \quad(13,37)$ \\
\hline$<=13(n=76)$ & Female & 271 & $(202,360)$ & $23 \quad(10,39)$ & $19 \quad(11,25)$ & 14 & $(6,19)$ & $19 \quad(10,30)$ & $30 \quad(13,41)$ \\
\hline$(n=80)$ & Male & 331 & $(220,532)$ & $20 \quad(4,38)$ & $20 \quad(10,31)$ & 17 & $(8,36)$ & $26 \quad(12,44)$ & $26 \quad(9,38)$ \\
\hline$(n=77)$ & Female & 283 & $(209,360)$ & $29 \quad(13,48)$ & $18 \quad(12,26)$ & 16 & $(12,23)$ & $23 \quad(11,35)$ & $28 \quad(9,42)$ \\
\hline$(n=118)$ & Male & 308 & $(227,593)$ & $21 \quad(0,46)$ & $22 \quad(10,37)$ & 18 & $(10,23)$ & $33 \quad(19,54)$ & $26 \quad(9,43)$ \\
\hline$(n=92)$ & Female & 266 & $(205,336)$ & $34 \quad(14,50)$ & $18 \quad(10,28)$ & 17 & $(10,22)$ & $24 \quad(10,34)$ & $31 \quad(12,46)$ \\
\hline$(n=85)$ & Male & 299 & $(140,417)$ & $24 \quad(1,48)$ & $22 \quad(12,33)$ & 19 & $(8,26)$ & $36 \quad(18,52)$ & $28 \quad(10,48)$ \\
\hline$(n=93)$ & Female & 263 & $(193,328)$ & $34 \quad(14,57)$ & $19 \quad(11,25)$ & 17 & $(8,23)$ & $24 \quad(13,33)$ & $30 \quad(9,44)$ \\
\hline$(n=63)$ & Male & 290 & $(224,509)$ & $26(0,49)$ & $21 \quad(8,31)$ & 19 & $(11,26)$ & $\begin{array}{ll}39 & (23,58)\end{array}$ & $30 \quad(16,46)$ \\
\hline$(n=86)$ & Female & 261 & $(204,349)$ & $32 \quad(12,45)^{4}$ & $19 \quad(10,30)$ & 17 & $(8,23)$ & $24 \quad(13,35)$ & $33 \quad(10,46)$ \\
\hline$>=18(n=103)$ & Male & 279 & $(210,432)$ & $26 \quad(7,45)$ & $22 \quad(10,34)$ & 19 & $(13,24)$ & $41 \quad(26,64)$ & $30 \quad(8,46)$ \\
\hline$>=18(n=121)$ & Female & 260 & $(203,384)$ & $31 \quad(19,49)^{5}$ & $19 \quad(13,29)$ & 17 & $(11,23)$ & $25 \quad(17,37)$ & $33 \quad(14,48)$ \\
\hline
\end{tabular}

'Run - 1000m for boys; $800 \mathrm{~m}$ for girls.

${ }^{2}$ Push up - Straight leg for boys; knee push up for girls.

${ }^{3}$ Grip - Right Hand Data

${ }^{4} n=27$

${ }^{5} n=72$ 
Table 3. Percentilles for Run* (in seconds) by Age Group

\begin{tabular}{|ccccccc|}
\hline Percentile & $<=13$ & $\mathbf{1 4}$ & $\begin{array}{c}\mathbf{1 5} \\
\text { MALES }\end{array}$ & $\mathbf{1 6}$ & $\mathbf{1 7}$ & $\mathbf{1 8 +}$ \\
$\mathbf{9 5}$ & 259 & 242 & 241 & 229 & 227 & 220 \\
$\mathbf{7 5}$ & 297 & 289 & 266 & 265 & 248 & 248 \\
$\mathbf{5 0}$ & 369 & 323 & 308 & 290 & 270 & 277 \\
$\mathbf{2 5}$ & 414 & 366 & 334 & 343 & 309 & 302 \\
$\mathbf{5}$ & 492 & 444 & $\mathbf{4 0 6}$ & 382 & 446 & 350 \\
& & & FEMALES & & & \\
$\mathbf{9 5}$ & 217 & 229 & 220 & 216 & 209 & 214 \\
$\mathbf{7 5}$ & 249 & 256 & 245 & 240 & 239 & 237 \\
$\mathbf{5 0}$ & 264 & 284 & 265 & 267 & 261 & 258 \\
$\mathbf{2 5}$ & 292 & 305 & 284 & 286 & 282 & 270 \\
$\mathbf{5}$ & 326 & 342 & 328 & 310 & 309 & 330 \\
\hline
\end{tabular}

* Run-1000m for boys; $800 m$ for girls.

Table 4. Percentiles for 30-sec Push up by Age Group

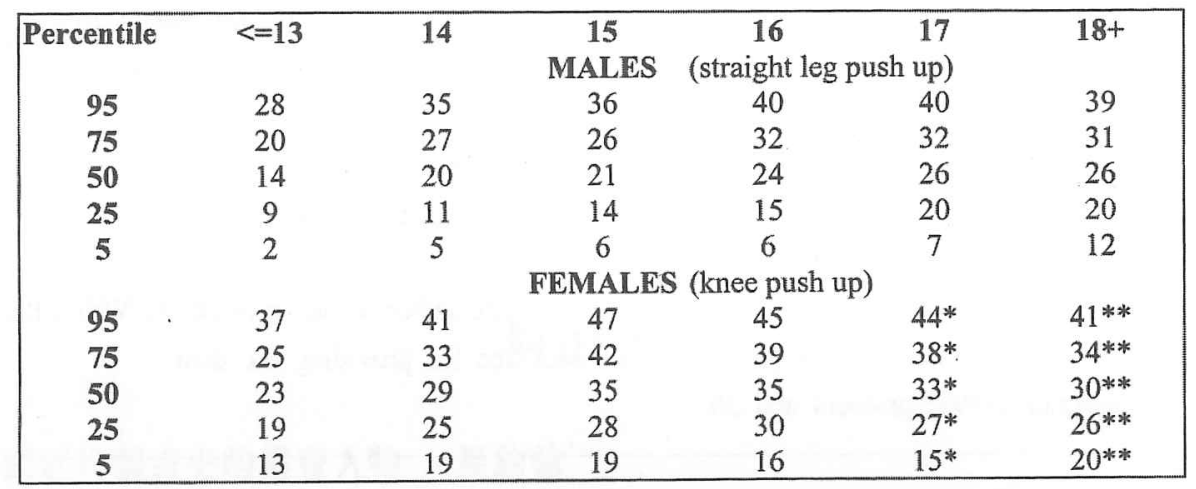

$* n=27$ (sample size)

** $n=72$ (sample size)

Table 5. Percentiles for 30-sec Sit up by Age Group

\begin{tabular}{|ccccccc|}
\hline Percentile & $<=13$ & $\mathbf{1 4}$ & $\begin{array}{c}\mathbf{1 5} \\
\text { MALES }\end{array}$ & $\mathbf{1 6}$ & $\mathbf{1 7}$ & $\mathbf{1 8 +}$ \\
$\mathbf{9 5}$ & 27 & 27 & 29 & 29 & 28 & 30 \\
$\mathbf{7 5}$ & 22 & 22 & 24 & 25 & 24 & 26 \\
$\mathbf{5 0}$ & 20 & 20 & 22 & 22 & 21 & 22 \\
$\mathbf{2 5}$ & 16 & 17 & 20 & 20 & 19 & 19 \\
$\mathbf{5}$ & 12 & 11 & 15 & 15 & 13 & 14 \\
& & & FEMALES & & & \\
$\mathbf{9 5}$ & 23 & 24 & 25 & 23 & 25 & 24 \\
$\mathbf{7 5}$ & 21 & 20 & 21 & 21 & 22 & 21 \\
$\mathbf{5 0}$ & 19 & 18 & 18 & 19 & 20 & 18 \\
$\mathbf{2 5}$ & 17 & 16 & 16 & 17 & 17 & 17 \\
$\mathbf{5}$ & 14 & 14 & 13 & 14 & 14 & 14 \\
\hline
\end{tabular}


Table 6. Percentiles for 30-sec Bailley Bridge Test by Age Group

\begin{tabular}{|ccccccc|}
\hline Percentile & $<=\mathbf{1 3}$ & $\mathbf{1 4}$ & $\begin{array}{c}\mathbf{1 5} \\
\text { MALES }\end{array}$ & $\mathbf{1 6}$ & $\mathbf{1 7}$ & $\mathbf{1 8}+$ \\
$\mathbf{9 5}$ & 19 & 21 & 22 & 23 & 24 & 23 \\
$\mathbf{7 5}$ & 17 & 18 & 20 & 20 & 21 & 21 \\
$\mathbf{5 0}$ & 15 & 17 & 18 & 19 & 20 & 20 \\
$\mathbf{2 5}$ & 13 & 15 & 17 & 17 & 18 & 18 \\
$\mathbf{5}$ & 9 & 11 & 14 & 13 & 13 & 15 \\
& & & FEMALES & & & \\
$\mathbf{9 5}$ & 18 & 20 & 21 & 21 & 21 & 20 \\
$\mathbf{7 5}$ & 16 & 18 & 18 & 19 & 19 & 19 \\
$\mathbf{5 0}$ & 15 & 17 & 17 & 18 & 17 & 18 \\
$\mathbf{2 5}$ & 13 & 15 & 15 & 16 & 16 & 16 \\
$\mathbf{5}$ & 9 & 12 & 13 & 12 & 11 & 14 \\
\hline
\end{tabular}

Table 7. Hand Grip (kgf) - Right hand By Age Group

\begin{tabular}{|ccccccc|}
\hline Percentile & $<=13$ & $\mathbf{1 4}$ & $\begin{array}{c}\mathbf{1 5} \\
\text { MALES }\end{array}$ & $\mathbf{1 6}$ & $\mathbf{1 7}$ & $\mathbf{1 8 +}$ \\
$\mathbf{9 5}$ & 35 & 40 & 45 & 49 & 50 & 54 \\
$\mathbf{7 5}$ & 25 & 30 & 38 & 42 & 42 & 46 \\
$\mathbf{5 0}$ & 20 & 25 & 32 & 37 & 40 & 41 \\
$\mathbf{2 5}$ & 17 & 21 & 27 & 31 & 35 & 37 \\
$\mathbf{5}$ & 13 & 17 & 21 & 22 & 30 & 29 \\
& & & FEMALES & & & \\
$\mathbf{9 5}$ & 28 & 30 & 30 & 31 & 33 & 34 \\
$\mathbf{7 5}$ & 22 & 26 & 27 & 27 & 27 & 28 \\
$\mathbf{5 0}$ & 19 & 23 & 25 & 24 & 25 & 25 \\
$\mathbf{2 5}$ & 16 & 20 & 21 & 22 & 22 & 23 \\
$\mathbf{5}$ & 11 & 15 & 16 & 18 & 17 & 18 \\
\hline
\end{tabular}

Table 8. Hand Grip (kgf) - Left hand By Age Group

\begin{tabular}{|ccccccc|}
\hline Percentile & $<=13$ & $\mathbf{1 4}$ & $\begin{array}{c}\mathbf{1 5} \\
\text { MALES }\end{array}$ & $\mathbf{1 6}$ & $\mathbf{1 7}$ & $\mathbf{1 8 +}$ \\
$\mathbf{9 5}$ & 35 & 38 & 45 & 47 & 49 & 53 \\
$\mathbf{7 5}$ & 25 & 27 & 35 & 41 & 41 & 44 \\
$\mathbf{5 0}$ & 20 & 24 & 30 & 34 & 38 & 40 \\
$\mathbf{2 5}$ & 15 & 21 & 25 & 29 & 34 & 35 \\
$\mathbf{5}$ & 12 & 15 & 20 & 21 & 26 & 28 \\
& & & FEMALES & & & \\
$\mathbf{9 5}$ & 28 & 29 & 29 & 29 & 32 & 32 \\
$\mathbf{7 5}$ & 21 & 24 & 25 & 25 & 25 & 27 \\
$\mathbf{5 0}$ & 18 & 21 & 23 & 23 & 23 & 24 \\
$\mathbf{2 5}$ & 16 & 19 & 20 & 21 & 20 & 21 \\
$\mathbf{5}$ & 11 & 15 & 15 & 15 & 16 & 17 \\
\hline
\end{tabular}

Table 9. Sit \& Reach (cm) By Age Group

\begin{tabular}{|ccccccc|}
\hline Percentile & $<=13$ & $\mathbf{1 4}$ & $\begin{array}{c}\mathbf{1 5} \\
\text { MALES }\end{array}$ & $\mathbf{1 6}$ & $\mathbf{1 7}$ & $\mathbf{1 8 +}$ \\
$\mathbf{9 5}$ & 36 & 36 & 38 & 43 & 46 & 42 \\
$\mathbf{7 5}$ & 28 & 32 & 31 & 34 & 36 & 35 \\
$\mathbf{5 0}$ & 24 & 26 & 27 & 26 & 30 & 30 \\
$\mathbf{2 5}$ & 18 & 22 & 22 & 21 & 24 & 24 \\
$\mathbf{5}$ & 15 & 16 & 16 & 17 & 18 & 16 \\
& & & FEMALES & & & \\
$\mathbf{9 5}$ & 39 & 41 & 43 & 43 & 44 & 45 \\
$\mathbf{7 5}$ & 34 & 34 & 37 & 35 & 37 & 37 \\
$\mathbf{5 0}$ & 30 & 29 & 31 & 31 & 34 & 34 \\
$\mathbf{2 5}$ & 26 & 23 & 27 & 26 & 30 & 30 \\
$\mathbf{5}$ & 20 & 17 & 18 & 16 & 21 & 21 \\
\hline
\end{tabular}

